\title{
SOME BASIC STRATEGIES IN TEACHING SPOKEN ENGLISH IN A NIGERIAN LANGUAGE ENVIRONMENT
}

\section{SHEHU SIDI IBRAHIM}

Dept. of Modern European Languages \& Literature, Usmanu Danfodiyo University.

\section{AWWAL IBRAHIM}

Department of English and Literature, Sokoto State University, Sokoto, Nigeria.

\begin{abstract}
Teaching pupils to speak English is more effectively achieved by allowing them to speak rather than by listening or reading. Pupils therefore must have the opportunity to express their likes and dislikes, to talk about their interests in living natural English. Without this training in the productive speech, skills pupils' ability to communicate in spoken English will be meager despite acquisition of knowledge of rules of pronunciation, grammar and sentence formation. To help pupils to develop speaking ability, this paper describes procedures of teaching speech as a communicative activity. At the same time, it suggests some activities that encourage pupils to exchange ideas spontaneously, and to practise fluency in asking questions while focusing attention on the information instead of the linguistic forms carrying that information.
\end{abstract}

\section{Preliminary Remarks:}

Contrary to what some scholars may suggest, there is no part of a human being which is specifically designed only for talking. The part of the body which produces the sounds of language are incidentally useful for this purpose, but they all have other duties to perform. From the biological point of view, these parts are older and have more important duties to perform, for example, breathing, chewing, swallowing, smelling, and such other activities. In the words of Evans (2014), 'Physiologically, speech is an overlaid function, or, to be more precise, a group of overlaid functions, nervous and muscular, that have come into being and are maintained for very different ends than its own'.

According to Ashby and Maidment (2011), the organs which we use for talking are basically the same, and work in the same way, in all human beings. No racial differences in their structure or in their manner of acting have ever been established. It follows from this that everybody who is free from abnormalities is capable of pronouncing anything. Thus, the unpronounceable sounds which some languages are alleged to possess are myths (Abercrombie 1967, Adegbite 2013).

More than half of the human body, from the head to the abdomen, is needed for the production of spoken language. There are three groups, or systems, of bodily organs which are brought into cooperation for this purpose: one group lies in the trunk, one in the throat, and one in the head, and they are usually known respectively as the respiratory system (the lungs, the muscles, the bronchial tubes and the wind pipe or trachea), the 
phonatory system (the larynx or voice box), and the articulatory system (the nose, the lips, and the mouth and its contents including especially the teeth and tongue).

\section{Teaching of spoken English}

The teaching of spoken English is an important aspect of second language methodology (Kailani and Al-Mutawa 1989). Spoken English drills are an integral part of effective English language teaching. These drills help pupils overcome problems that arise from the interference of the mother tongue. Thus, when a Nigerian child is first introduced to English at the age of five or probably six, he will have acquired the phonological system of his first language. If he has no remedial work on spoken English at an early stage of learning the second language, he will establish incorrect forms of English sounds. Features and habits of mother tongue will condition the way he speaks English. It is essential, therefore, to start teaching the sounds and the international patterns of English from the first day of learning the language. This procedure will foster good habits of speaking in young learners. Practice in these early stages of learning should, however, be limited to minimal pairs or to the repetition of individual words or patterns.

With advanced learners, spoken English practice may be done within the context of more difficult drills. For example, learners should be exposed to living speech (live or recorded)), such as conversations, radio broadcasts, plays and the like. Such spoken English drills and activities will help pupils identify and discriminate English sounds. They also enable them to hear English voices other than the teacher's, and they provide the pupils with a model for imitation.

However, the teaching of spoken English which involves individual sounds, liaison between these sounds, stress, rhythm and intonation, may run into problems. These may include the availability of a competent teacher, authentic materials, adequate exposure to good models and constant practising.

According to Carr (2013), the teacher must have a basic understanding of how the sound system of English works. He went on to say that such teacher should know the problems which may affect the learning process such as the substitution of the phoneme /p/ and /f/ as with the case of a Hausa learner, for example. This contrastive knowledge will help the teacher to identify problem areas and to handle them more effectively. To fulfill this goal, the teacher has to design learning activities that will elicit pupil's responses, requiring the use of vocabulary items or grammatical 
structures which contain the target sounds they wish them to practise. In this way the teacher contextualizes spoken English and ensures meaningful communication which is the central purpose for language study.

For pedagogical purposes, we shall review, in this section, (a) segmental phonemes, vowels and consonants, (b) suprasegmentals including stress, intonation and internal juncture, (c ) English sounds (including consonant clusters) that do not exist in Nigerian languages indicating at the same time, habits and features of mother tongue that might affect spoken English, and finally (d) some spoken English drills and activities suggested to overcome the influence of the first language interference.

\section{Vowels}

Traditionally, as Lyons (1981) puts it, vowels have been specified in terms of the position of the highest point of the tongue and the position of the lips.

In the table above, they are divided into seven short and five long vowels. An alternative way of organizing them, is according to where (in the mouth), they are produced. This method allows us to describe them as front, central and back. We can qualify them further by how high the tongue and lower jaw are when we make these vowel sounds, and by whether our lips are rounded or spread, and finally by whether they are short or long. This scheme shows the following arrangement:

/i:/ - cream, seen (long high front spread vowel)

/ I/ - bit, silly (short high front spread vowel)

/e/ - bet, head (short mid front spread vowel); this may also be shown by the symbol /e/

/æ/ - cat, dad (short low front spread vowel)

\section{Central vowels}

/3: /- burn, firm (long mid central spread vowel); this may also be shown by the symbol /ə: /.

/ə/ - about, clever (short mid central spread vowel); this is sometimes known as schwa, or the neutral vowel sound - it never occurs in a stressed position.

$/ \Lambda /$ - cut, nut (short low front spread vowel); this vowel is quite uncommon among speakers in the Midlands and further north in Britain. 


\section{Back vowels}

/u:/ - wool, glue (long high back rounded vowel)

$/ \mho /$ - put, soot (short high back rounded vowel); also shown by $/ \mathrm{u} /$

/ว: / - corn, call (long mid back rounded vowel) also shown by /o: /

$/ \mathrm{p} /-\mathrm{dog}$, rotten (short low back rounded vowel) also shown by /o/

/a:/ - hard, far (long low back spread vowel)

We can also arrange the vowels in a table or even depict them against a cross-section of the human mouth. Here is an example of a simple table:

\begin{tabular}{llll}
\hline & Front & Central & Back \\
\hline High & I I: & & U u: \\
Mid & E & ə 3: & ग: \\
Low & $Æ$ & $\Lambda$ & D a: \\
\hline
\end{tabular}

Because of their high frequency and a structure which is different from that of the Nigerian languages, English vowels constitute one of the difficult problems in mastering the sound system of English.

Of the eight English diphthongs (/ei/, /əu/, /ai/, /วi/, /au/, /iə/, /еə/, /uə/) two constitute the greatest problem to the Nigerian learner of English. These are: /ei/ and /ou/. They are often mispronounced owing to interference from the mother tongue.

The diphthong /ei/ is often replaced by the pure vowel /e/. Thus, /breik/, /rein/, /greit/, /meik/, /weik/, /keik/and /dei/ are pronounced by most Nigerian learners of English as /bre/, /ren/, /gret/, /mek/, /wek/, /kek/ and /de/.

Oral Tests for the /ei/ diphthong

\begin{tabular}{ll}
\hline Sail & Sell \\
Wait & Wet \\
Fail & Fell \\
Late & Let \\
Later & Letter \\
Pain & Pen \\
\hline
\end{tabular}

Oral Tests for the / ou/ diphthong

\begin{tabular}{ll}
\hline Sail & Sell \\
Wait & Wet \\
Fail & Fell \\
Late & Let \\
\hline
\end{tabular}


Later Letter

Pain Pen

\section{Consonants}

In the formation of consonants, the airstream through the vocal tract is obstructed in some way. Consonants can be classified according to the place and manner of this obstruction. Some of the possible places and manner of articulation are indicated below:

Glottal articulation - articulation by the glottis. We use this for one consonant in English. This is $/ \mathrm{h} /$ in initial position in house or hope.

Velar articulation - we do this with the back of the tongue against the velum. We use it for initial hard /g/ (as in go) and for final / $\mathrm{y} /$ (as in sing).

Palatal articulation - we do this with the front of the tongue on the hard palate. We use it for /dz/ (as in jam) and for $/ \int /$ (as in sheep or sugar).

Alveolar articulation - we do this with the tongue blade on the alveolar ridge. We use it for /t/ (as in teeth), /d/ (as in death) /z/ (as in zebra) /n/ (as in $n o$ ) and /l/ (as in light).

Dental articulation - we do this with the tip of the tongue on the back of the upper front teeth. We use it for $/ \theta /$ (as in think) and /ð/ (as in that). This is one form of articulation that we can observe and feel ourselves doing.

Labio-dental articulation - we do this with the lower lip and upper front teeth. We use it for /v/and /f/ (as in vampire and fire).

Labial articulation - we do this with the lips for /b/ (as in boat) and /m/ (as in $m o s t$ ). Where we use two lips (as in English) this is bilabial articulation.

This scheme gives us a different arrangement into stop (or plosive) consonants, affricates, fricatives, nasal consonants, laterals and approximants.

Stop consonants (so-called because the airflow is stopped) or plosive consonants (because it is subsequently released, causing a rushing out of air and a burst of sound) are:

Bilabial voiced /b/ (as in boat) and voiceless /p/ (as in post)

Alveolar voiced /d/ (as in dad) and voiceless /t/ (as in tap)

Velar voiced /g/ (as in golf) and voiceless /k/ (as in cow) 
Affricates are a kind of stop consonants, where the expelled air causes friction rather than plosion. They are palatal $/ \mathrm{t} \int /$ (as in cheat) and /dz/ (as in jam).

Fricatives come from restricting, but not completely stopping, the airflow. The air passes through a narrow space and the sound arises from the friction this produces. They come in voiced and unvoiced pairs:

Labio-dental voiced $/ \mathrm{v} /$ (as in vole) and unvoiced /f/ (as in foal)

Dental voiced /ð/ (as in those) and unvoiced $/ \theta /$ (as in thick)

Alveolar voiced /z/ (as in zest) and unvoiced /s/ (as in sent)

Palatal voiced /3/ (as in the middle of leisure) and unvoiced / $/$ / (as at the end of trash).

Nasal consonants involve closing the articulators but lowering the uvula, which normally closes off the route to the nose, through which the air escapes. There are three nasal consonants in English:

Bilabial $/ \mathrm{m} /$ (as in mine)

Alveolar $/ \mathrm{n} /$ (as in nine)

Velar $/ \mathrm{y} /$ (as at the end of sing)

Lateral consonants allow the air to escape at the sides of the tongue. In English there is only one such sound, which is alveolar /l/ (as at the start of lamp)

Approximants do not impede the flow of air. They are all voiced but are counted as consonants chiefly because of how they function in syllables.

They are:

Bilabial /w/ (as in water)

Alveolar $/ \mathrm{r} /$ (as in road)

Palatal /j/ (as in yet)

\section{Problematic Consonants for most Nigerian learners of English}

The teacher must have a basic understanding of how the sound system of English works. Moreover, he should know the problems which may affect the learning process. Let us now take a look at some instances of some English consonant phonemes substitutions in Hausa, Yoruba and Igbo.

$\begin{array}{lll}\text { Hausa substitutions of some consonants } \\ / \mathrm{p} / \quad> & {[\mathrm{p}],[\mathrm{f}],[\Phi]} \\ / \mathrm{p} / & > & {[\mathrm{f}],[\mathrm{p}],[\Phi]} \\ / \mathrm{b} / & > & {[\mathrm{b}],[\mathrm{v}]} \\ / \mathrm{v} / & > & {[\mathrm{v}],[\mathrm{b}]} \\ / ð / & > & {[ð],[\mathrm{z}]} \\ / \theta / & > & {[\theta],[\mathrm{s}]}\end{array}$




\section{Yoruba substitutions of some consonants}

$\begin{array}{lll}/ \mathrm{v} / & > & {[\mathrm{v}],[\mathrm{f}]} \\ / \theta / & > & {[\theta],[\mathrm{t}],[\mathrm{t}]} \\ / \mathrm{d} / & > & {[\mathrm{d}],[\mathrm{d}],[\mathrm{d}]} \\ / \mathrm{d} / & > & {[\mathrm{d}],[\mathrm{b}]} \\ / \mathrm{f} / & > & {[\mathrm{f}],[\mathrm{f}]} \\ / \mathrm{h} / & > & {[\mathrm{h}], \text { deleted }} \\ / \mathrm{z} / & > & {[\mathrm{z}],[\mathrm{s}]}\end{array}$

\section{Igbo substitutions of consonants}

$\begin{array}{ll}/ \theta / \quad> & {[\theta],[\mathrm{t}],[\mathrm{t}]} \\ / \mathrm{d} / \quad> & {[ð],[\mathrm{d}],[\mathrm{d}]} \\ / \mathrm{hj} /(\text { human }) & {[\mathrm{h}]} \\ / \mathrm{pj} / \text { (pupil) } & {[\mathrm{p}]}\end{array}$

\section{Syllable structure}

Syllable in English can have an onset made up made up of no consonant at all or up to three consonants, an obligatory vowel as a peak, and a coda made up of no consonant at all or up to three consonants. This linguistic phenomenon is quite different from that of Nigerian languages where vowels follow consonants and consonants follow vowels in a VCVC arrangement. This perhaps explains why Nigerian learners of English tend to insert (epenthesis) vowel sounds in between consonant clusters to make the pronunciation easier as in the examples that follow:

Epenthetic /i/

$\begin{array}{lllll}\text { Praise } & > & \text { [praiz] } & > & {[\text { pireis] }} \\ \text { Scratch } & > & {[\text { skraff] }} & > & {[\text { sikiraff] }} \\ \text { Pray } & > & {[\text { prei] }} & > & {[\text { pirei] }} \\ \text { Green } & > & {[\text { gri:n] }} & > & {[\text { giri:n] }} \\ \text { Plate } & > & {[\text { pleit }]} & > & {[\text { pileit] }}\end{array}$

Epenthetic /u/

$\begin{array}{lllll}\text { Floor } & > & {[\text { flo: }]} & > & {[\text { fulo: }} \\ \text { From } & > & {[\text { from }]} & > & {[\text { furom }]} \\ \text { Black } & > & {[\text { blæk }]} & > & {[\text { bulak] }} \\ \text { School } & > & {[\text { sku:l] }} & > & {[\text { sukul }]} \\ \text { Broom } & > & {[\text { bru:m }]} & > & {[\text { buru:m }]}\end{array}$

It is clear from the above examples that the problem of spoken English is attempted to be solved by the intrusive /i/ and /u/ phonemes. 


\section{Stress}

Stress, in the words of Cattell (2007), is the amount of emphasis we put on a syllable. In other words, stress is the relative degree of loudness of a syllable or a word, or of a syllable within an utterance. Stress affects whole syllables rather than single segments. The effect of stressing a syllable is to make it more prominent, more audible than neighbouring syllables. According to Ashby and Maidment (2011), stress is a relational feature, unlike features such as place and manner features or vowel quality features. Thus, while it makes sense to ask whether an isolated consonant is, for example, bilabial, or whether an isolated vowel is high or low, it can never be sensible to ask whether an isolated syllable is stressed. The way in which a stressed syllable is made more prominent than other syllables in the utterance is usually by a combination of factors such as length, loudness and pitch. Therefore, usually a stressed syllable is longer and louder than its neighbours and may be marked by some pitch movement or new level in pitch. These are usually called word stress and sentence stress.

\section{Word stress}

Word stress in English can be phonemic. Putting it differently, word stress refers to the amount of emphasis on a syllable, and it ranges from very strong to very weak. A strong stress can involve various factors, including loudness, duration and intonation. Compare the words buck and bucket. There is a strong stress on the word buck, as there is on all monosyllables produced in isolation. But when there are two or more syllables, there will most often be a differentiation in the amount of stress put on the different syllables. If you say bucket aloud, you can hear that the first syllable, buck-, is more heavily stressed than the second one, -et. In consequence, the vowel in -et is reduced to the neutral vowel, [Ә] - also called 'schwa' - so that the -et does not rhyme with bet.

The assignment of stress in words is a complex technical issue (Crystal 2010). There are some words in which the stress is different depending on whether the item is a verb or a noun. For example, the noun PERmit has a strong stress on the first syllable, but the verb permit has it on the second. Another good example of this is the word conduct. As a noun, the word is accented on the first syllable. Here the noun CONduct is pronounced /'kond $\Lambda \mathrm{kt} /$. However, as a verb, the word is stressed on the second syllable. For example, 'You should conduct yourself very well throughout the period of this lecture.' Here the verb conduct is pronounced / kənd $\Lambda \mathrm{kt} /$. The same difference on the noun and that on the corresponding verb 
occurs with export, protest, progress, suspect, torment and numerous other words.

Two-or -more syllable words have their own stress systems, as follows:

Two-syllabled words are stressed mostly on the first syllable, e.g.: broken, handsome, curtain, picture, farmer, baby, etc.

Two-syllabled words beginning with a prefix of some kind (a-, per-, dis-, re-, post-, ex-, anti-, ante-, etc.) are usually stressed on the second syllable. Examples: a'way, be'hind, per'sist, dis'miss, re'ply, post'date, ex'ceed, anti-crime, ante'natal, etc.

Some three syllabled words have their stress on the middle syllable. Examples: im'portant, re'ceiver, ap'proval, con'dition, de'velop, etc.

Some other three-syllabled words are stressed on the first syllable. Examples: 'wonderful, 'absolute, 'ignorant, 'covering, 'hopefully, etc.

Four-or more-syllabled words have often two stresses- secondary and primary on the on the third syllable from the end, e.g.: eco'nomic, potential, inorganic.

Combinations are treated as one word and usually have their stress on the first part. Examples: 'dining room, 'handbag, 'notebook, 'inkpot, 'bookcase, 'classroom, 'football, etc.

Nouns modified by other words have their own norm stress patterns, as in the following groups: a 'stone 'building, a 'cotton 'shirt, a 'metal "pot, a 'wooden 'door, an 'old 'house, etc.

Words that function as both nouns and verbs have the stress on the first syllable when they are nouns and on the second syllable when they are verbs. Examples: contrast, extract, increase, protest, progress, record, insult, export, import, refuse.

The above categories of words are by no means exhaustive. Many English words have to be learned through imitation and practice because their stress distribution is irregular. The teacher should thus expose his pupils to authentic speech as spoken by its native speakers, and should speak at a normal speed to encourage them to follow his example. Taped material is helpful in this respect, especially if it is practiced in the language laboratory.

In most Nigerian languages including Pidgin stress falls on the second syllable of a word containing two syllables (Adetugbo 1993). This stress habit often causes problems to the Nigerian learner of English because it is usually retained, thereby affecting the acquisition of the new sound system. This difficulty is obvious with two-syllable words (such as subject, record, rebel, project, etc.) that may be used as either nouns or 
verbs, with a difference in stress to indicate the difference in meaning. In the absence of such a process in Nigerian languages, pupils often confuse these two syllable words.

A combination of two nouns also constitutes a problem to a learner of English in Nigeria because a shift in stress makes a difference in meaning. For example:

A green house $=$ a glassed enclosure for cultivating plants A green house $=$ a house that is green in colour

An English teacher $\quad=$ a teacher of the English language An English teacher $\quad=$ a teacher who is from England

\section{Sentence Stress}

In above, we described stress as the amount of emphasis we put on a syllable which ranges from very strong to very weak. Stress is, in fact, more complex than that. Once we put words into phrases and sentences, the stress that they have in isolation frequently changes. For example, if we are asked to pronounce the word that, we will put a strong stress on it; but if we use the same word in the sentence Did I tell you that I went to the market yesterday? We will almost certainly reduce that to a weakly stressed syllable and reduce the vowel from its normal quality to that of a neutral vowel. On the other hand, if we say I think I'll take that one, indicating a particular shirt or cap in a shop, we will be likely to give the vowel in that its full quality and stress it strongly. We can also give a strong stress to any word that we want to contrast with some other word. These are some of the skills that Nigerian learners of English should learn. Take the following sentence as another example: The driver turned to the right. The teacher can say each of the versions of the sentence aloud using the stress word marked in bold and then match the sentence version to the meaning below. The answers to this quiz are written below the sentence versions.

The driver turned to the right.

The driver turned to the right.

The driver turned to the right.

Who turned to the right?

What did the driver do?

Did the driver turn to the left?

Meaning changes depending on which word is stressed. The learner should not be afraid to exaggerate the stress in English. Crystal ( 2014) is of the view that speakers of English often use this device to add meaning 
to a sentence. It is very possible that when a particular second language speaker thinks that he is exaggerating, it will sound quite natural to native speakers.

As a general rule, the words that are stressed, in a normal sentence are adverbs, adjectives, main verbs or nouns. On the converse, articles, auxiliary verbs, pronouns, prepositions and conjunctions receive tertiary or weak stress. However, the emphatic 'do' take primary stress (Ndahi 1982; Katamba 1992 and Akmajian et, al. 2001).

\section{The Last words}

Learning to speak is a lengthy and complex process. Many foreign language teachers realize that fluency in speaking is the most difficult skill to develop. In addition to linguistic and cultural knowledge, there are other requirements that should be available in order to develop this skill. They include the following:

- A competent teacher who is fluent in conversation.

- Appropriate classroom atmosphere, which is conducive to oral communicative acts, and pupils feel at ease and relaxed.

- $\quad$ Ample opportunity for pupils' participation.

- Clear objectives in speaking so that pupils can think of the ideas they wish to express.

- $\quad$ Knowledge of the appropriate functional expressions.

- A variety of learning activities including manipulative drills, guided conversation, communicative practice and free oral work such as discussion groups, debates, planned discussions, skills competitions, etc.

- Contextualized language in terms of who is speaking to whom, where and why.

All of these requirements are essential in developing spoken English.

\section{Concluding Remarks}

It is a known fact that the time available for typical spoken English lesson (if it does exist) in our schools and colleges is quite inadequate. The teacher thus has to remedy his pupils' spoken English through identifying their most common problems and giving them practice exercises and activities, rather than rules. 
Furthermore, the teacher should design spoken English drills and learning activities that will elicit the responses of the pupils. For preliminary work the teacher may start with minimal- pair drills which are very useful for initial ear training; but later, with advanced learners, spoken English work may be done within the context of communicative activities.

In teaching spoken English (whether segmental or supra-segmentals), one of the best methods, perhaps, is imitation (Wilkins 1978). That is, the teacher says something and the pupils imitate him. However, imitation method should be handled with care otherwise it could unintentionally mislead the learner and/or the teacher in producing the wrong feedback. Perhaps that is why Abbott and Wingard (1981) cautioned that unless where the learner is fortunate to have unimpeded view of the teacher (lip movement, rounding, closure, etc.) tendency is that he would be forced to rely on auditory clues which themselves are fraught with a lot of uncertainties. For example, the learner may wrongly perceive the sounds made and thus produce the wrong sound or that the teacher himself may wrongly perceive what he hears from the learner. Either way, the result of this misinterpretation would be undesirable and therefore counter productive to effective teaching and learning.

A possible approach that could avoid the possibility of occurrence of the above problems would be the articulatory descriptive strategy. Here the teacher gives the description of the place and manner of the articulation of the sounds under discussion. For example, in the teaching of the distinction between voiceless and voiced sounds the teacher can do the following: Ask the learner to put his finger on his neck just below his chin — on his Adam's apple. Now ask him to say the pairs of sounds. In each pair of the first, is a voiceless sound and his finger will feel no vibration. The second is voiced and he should feel the vibration: / p/; /b; $/ \mathrm{t} / ; / \mathrm{d} ; / \mathrm{k} / ; / \mathrm{g} / ; / \mathrm{s} / ; / \mathrm{z} /$ and so on. In the teaching of aspirated and non aspirated sounds, the following descriptive approach is recommended: Ask the learner to put a piece of paper in front of his mouth and make sure that a puff of air moves the paper when he produces any of the consonant sounds $(/ \mathrm{p} / ; / \mathrm{t} / ; / \mathrm{k} /)$ word initially. Similar strategy could be adopted in the teaching of the remaining sounds where applicable. 


\section{References}

Abbott, G. and Wingard, P. (ed.) (1981). The Teaching of English as an International Language (A Practical Guide): Collins: Glasgow and London.

Abercrombie, D. (1967). Elements of General Phonetics: Edinburgh University Press.

Adegbite, W. (2013): The Psycholinguistics of English Language in Nigeria: Kraft Books Limited. Nigeria.

Adetugbo, B. (1993). English Phonetics: A Course text: Department of English, University of Lagos, Nigeria.

Akmajian, A. et. al (1995): Linguistics: An introduction to language and Communication, MIT Press, Cambridge, MA, USA.

Al-Mutawa, N. and Kailani, T. (1989). Methods of Teaching English to Arab Students: Longman: London.

Carr, P. (2013). English Phonetics and Phonology: An Introduction: Willey-Blackwell.

Crystal, D. (2010). The Cambridge Encyclopedia of Language: Cambridge: Cambridge University Press.

Crystal, D. (2014). English as a Global Language: Cambridge: Cambridge University Press.

Evans, V. (2014). The Language Myth: Why Language is not an Instinct: Cambridge: Cambridge University Press.

Katamba, F. (1989). An Introduction to Phonology, Longman: London and New York.

Maidment, J. and Ashby, M. (2011). Introducing Phonetic Science: Cambridge: Cambridge University Press.

Ndahi, K.S. (1982). Second Language Acquisition in Childhood: A case study: Unpublished $\mathrm{PhD}$ Thesis, (2 Volumes), Ahmadu Bello University, Zaria, Nigeria. 